\title{
MENINGKATKAN SOSIAL EMOSIONAL ANAK PADA KELOMPOK B MELALUI PERMAINAN TRADISIONAL BAKIAK DI TK AT-TAQWA KEJAWAN GRUJUGAN BONDOWOSO
}

\author{
Halimatus Sakdiyah \\ Pendidikan Islam Anak Usia Dini,Tarbiyah, Universitas Ibrahimy \\ E-mail: htutus947@gmail.com
}

\begin{abstract}
ABSTRAK: Tujuan pada penelitian ini adalah mengetahui pelaksanaan dan hasil kegiatan permainan tradisional bakiak dapat meningkatkan kemampuan sosial emosional anak pada kelompok B di Tk AtTaqwa Kejawan Grujugan Bondowoso. Peneliti menggunakan pendekatan Penelitian Tindakan Kelas (PTK) dengan subyek penelitian anak didik kelompok B Tk At-Taqwa Kejawan Grujugan Bondowoso. Penelitian ini dilaksanakan dalam dua siklus dan hasil penelitian menunjukkan bahwa ada peningkatan sosial emosional anak melalui permainan tradisional bakiak yakni sebelum tindakan $19 \%$, siklus I mencapai $62 \%$, siklus II mencapai $81 \%$. Kesimpulan dari penelitian ini adalah melalui permainan tradisional bakiak dapat meningkatkan sosial emosional anak kelompok B di Tk At-Taqwa Kejawan Grujugan Bondowoso.
\end{abstract}

Kata Kunci: Sosial Emosional; Permainan Tradisional

\begin{abstract}
The purpose of this study was to determine the implementation and results of traditional clogs game activities to improve children's emotional social abilities in group B at At-Taqwa Kejawan Grujugan in Bondowoso. Researcher used the Classroom Action Research (CAR) approach with research subjects in group B Tk At -Taqwa Kejawan Grujugan Bondowoso. This research was conducted in two cycles and the results showed that there was an increase in children's emotional social through traditional clogs,that before the action $19 \%$, cycle I reached $62 \%$, cycle II reached $81 \%$. The conclusion of this research is that through traditional clogs games can improve the emotional social of B group children at Tk At Taqwa Kejawan Grujugan Bondowoso.
\end{abstract}

Keywords: Emotional Social; Traditional Game

\section{PENDAHULUAN}

Perkembangan sosial emosional merupakan perkembangan yang tidak dapat terpisahkan antara satu dengan yang lain, karena perkembangan emosi harus bersinggungan dengan perkembangan sosial anak. Demikian pula sebaliknya, perkembangan sosial harus melibatkan emosional. Sebab, keduanya terintegrasi dalam bingkai kejiwaan yang utuh. Menurut Lawrence, emosi adalah kondisi kejiwaan manusia yang disebabkan oleh sifat psikis kejiwaan. Maka emosi dapat dikaji melalui letupan - letupan emosional atau gejala dan fenomena - fenomena seperti kondisi bersedih, gembira, gelisah, membenci, dan lain sebagainya (Suyadi, 2010: 109).

Perkembangan emosi sosial memiliki peran yang sangat penting dalam menentukan hubungan sosial anak dimasa depan dan pola prilaku terhadap orang lain untuk membentuk perkembangan sosial anak dengan baik tentu saja harus dimulai sejak dini (Busthomi, 2012: 32). Namun, tidak demikian dengan para siswa di TK AtTaqwa Kejawan Grujugan Bondowoso khususnya pada siswa kelompok B. Perkembangan sosial emosional antar anak yang satu dengan yang lain masih kurang. Kepekaan anak untuk memahami perasaan 
orang lain ketika berinteraksi masih kurang, ada anak yang aktif hanya mau berteman dengan yang aktif saja sedangkan yang pasif tidak. Sehingga anak yang aktif tidak tau bagaimana anak yang pasif mengekspresikan gembiranya seperti apa atau lagi sedih seperti apa. Peneliti menggunakan permainan tradisional bakiak sebagai jembatan untuk mengembangkan perkembangan sosial emosional anak.

TK At-Taqwa Kejawan Grujugan Bondowoso khususnya pada kelompok B jarang sekali siswa mengenal permainan tradisional apalagi permainan tradisional bakiak. Seiring dengan perkembangan zaman permainan dari segi bentuknya semakin menarik. Mayoritas dari permainan yang ada sudah menggunakan teknologi. Sehingga permainan tradisional semakin terpuruk dan anak- anak tidak mengenalnya. Pemanfaatan permainan tradisional sebagai media pembelajaran jarang sekali guru - guru menggunakan khususnya bagi guru - guru anak usia dini. Permainan tradisional pada dasarnya permainan yang bersifat sederhana dan mengandalkan kekompakan dari masing masing peserta dalam kegiatan bermain. Salah satu contohnya adalah permainan tradisional bakiak.

Bentuk bakiak yang digunakan dalam bermain sangat berbeda dengan bakiak yang digunakan sebagai alas kaki. Sebagai media permainan, bakiak berbentuk panjang dan memiliki tali lebih dari satu. Jumlah tali yang terpasang pada bakiak panjangnya disesuaikan dengan jumlah para pemain.. Panjang bakiak dapat mencapai satu meter atau lebih. Kayu yang digunakan sangat ringan untuk memudahkan mengangkat dan menjalankannya. Manfaat dari permainan tradisional bakiak ini adalah untuk menentukan hubungan sosial emosional anak dan pola prilaku terhadap orang lain serta mengembangkan empati dan kepedulian terhadap teman sebayanya. Sehingga permainan tradisional anak akan sangat menarik digunakan untuk meningkatkan sosial emosional anak di TK At-Taqwa Kejawan Grujugan Bondowoso.

\section{METODE PENELITIAN}

Penelitian ini menggunakan jenis penelitian tindakan kelas. Menurut Sa'dun penelitian tindakan kelas adalah investigasi dalam menemukan dan proses pemecahan masalah secara bersiklus untuk meningkatkan kualitas pembelajaran dan hasil pembelajaran dikelas (Sukidin, 2002: 37). Peneliti berorientasi pada pengkajian masalah - masalah praktis yang dihadapi guru di dalam kelas dari mulai perencanaan, tindakan, observasi, dan refleksi yang hasilnya dapat dipraktekkan oleh guru itu sendiri dalam rangka memperbaiki metode pembelajaran sehari - hari.

Sumber data pada penelitian ini yaitu subjek data yang diperoleh dan diklasifikasikan menjadi orang atau person, tempat atau place, dan symbol atau paper. Subjek dalam penelitian ini adalah anak usia di usia 5- 6 tahun. Penelitian dilakukan dikelas B dengan jumlah anak 16 orang yang mana terdiri dari 11 perempuan dan 5 laki laki. Dengan lokasi penelitian disekolah TK At Taqwa Kejawan Grujugan Bondowoso.

\section{HASIL PENELITIAN Kondisi Prasiklus}

Dalam melakukan observasi, peneliti juga melihat daftar nilai hasil belajar anak dalam sehari - harinya. Hal tersebut dilakukan sebagai bahan pertimbangan dalam meningkatkan perkembangan anak ketika pelaksanaan tindakan penelitian. Peneliti juga melakukan wawancara kepada guru tentang seputar perkembangan anak dikelas. Hasil wawncara menunjukkan bahwa guru dalam proses belajar mengajar dalam mengembangkan perkembangan anak sering menggunakan metode menggambar dan mewarnai.

Dari hasil pengumpulan data dari observasi dan wawancara dengan guru kelas B maka diketahui ada beberapa anak yang masih belum mencapai KKM sebelum peneliti menerapkan kegiatan permainan 
tradisional bakiak dalam meningkatkan perkembangan sosial emosional anak.

\section{Tabel 1. Data Nilai Prasiklus}

Hasil belajar pada kelompok B di TK At Taqwa Kejawan - Grujugan - Bondowoso pada pra siklus cenderung rendah. Terbukti dari hasil nilai pra siklus hanya 3 anak dari 16 anak yang telah mencapai target ketuntasan anak dalam mencapai perkembangan. Dari hasil ini, maka semua anak baik yang sudah mencapai perkembangan ataupun belum perlu mendapat perhatian agar nilainya dapat meningkat dan dapat mencapai ketuntasan dalam mencapai perkembangan.

\section{Pelaksanaan Siklus 1}

\section{a. Perencanaan}

\begin{tabular}{|r|c|c|c|}
\hline No & Kategori Nilai & $\begin{array}{c}\text { Jumlah } \\
\text { Anak }\end{array}$ & Presentase \\
\hline 1 & Baik & 3 & $19 \%$ \\
\hline 2 & Cukup & 7 & $44 \%$ \\
\hline 3 & Kurang & 6 & $38 \%$ \\
\hline \multicolumn{2}{r|}{ Total } & 16 & $100 \%$ \\
\hline
\end{tabular}

Kegiatan Pembuka

1. Menerapkan SOP pembukaan

2. Membaca doa - doa dan surat - surat pendek

3. Mempercayai adanya Tuhan melalui Ciptaan-Nya

4. Menyebutkan macam - macam permainan

5. Menyebutkan macam - macam permainan tradisional

Kegiatan Inti

1. Menerapkan SOP inti

2. Meminta anak menunjukkan tangan kanan dan kiri serta kaki kanan dan kaki kiri

3. Meminta anak untuk memainkan bakiak

4. Kelompok bermain ditentukan peneliti

5. Menyebutkan nama - nama teman kelompoknya
6. Menyebutkan bentuk bakiak secara kelompok

Kegiatan Penutup

1. Penerapan SOP penutup

2. Mengkonfirmasikan kegiatan untuk esok hari

Alat dan bahan yang digunakan dalam permainan adalah:

1. Batu

2. Permainan bakiak

3. Nama pengenal bagi anak

b. Pelaksanaan

Pada tahapan pelaksanaan tindakan kelas, peneliti menggunakan permainan tradisional bakiak untuk proses pembelajaran disesuaikan dengan rencana pelaksanaan pembelajaran harian (RPPH) yang telah dibuat peneliti sebelumnya.

c. Observasi

Pada tahap kegiatan awal pelaksanaan kegiatan dilakukan didalam kelas. Yang mana di TK At Taqwa jika hari jum'at semua kelas A dan B di gabung menjadi satu untuk membaca do'a dan surat pendek waktunya dari jam 07.10 WIB sampai dengan jam O8.0o WIB.

Setelah selesai para siswa kembali ke kelas masing - masing untuk mengikuti pembelajaran seperti biasanya. Dengan sigap guru memerintah anak untuk membaca do'a sebelum belajar setelah itu langsung memperkenalkan peneliti. Peneliti membuka dengan menyapa anak dengan sebuah nyanyian good morning everybody, Setelah bernyanyi peneliti memberikan nama pengenal kepada tiap - tiap anak di kelompok B yang dibantu oleh guru kelas, tujuannya agar peneliti dapat mengenal satu persatu dari anak anak tersebut tanpa betanya kepada guru kelas. Selesai pembagian kartu nama peneliti menanyakan kepada anak siapa yang suka bermain didalam kelas maupun di rumah ternyata semuanya suka bermain. 
Peneliti mencoba memberikan rangsangan terhadap anak - anak tentang permainan tradisional yang sering dipakai dalam acara 17 agustus, kemudian peneliti memancing lagi dengan sebuah pertanyaan permainan tradisional kelereng dan $\mathrm{ABC}$, jawabannya 'tidak tahu". Ini merupakan suatu dampak dari permainan teknologi sehingga anak lupa terhadap permainan tradisional yang sudah ada dari nenek moyang kita. Setelah itu, peneliti mengenalkan permainan tradisional bakiak kepada siswa dan meminta pada peserta didik untuk bermain diluar kelas.

Tabel 2. Hasil Observasi Kemampuan Sosial Emosional Anak Siklus I

\begin{tabular}{|c|c|c|c|}
\hline No. & Aspek yang diamati & $\begin{array}{l}\text { Siklus } \\
\text { I }\end{array}$ & Kriteria \\
\hline 1. & $\begin{array}{l}\text { Anak mau bermain } \\
\text { meskipun bukan } \\
\text { teman mainnya. }\end{array}$ & $81 \%$ & Baik \\
\hline 2. & $\begin{array}{l}\text { Anak mau } \\
\text { melangkah sesuai } \\
\text { arah kiri dan kanan } \\
\text { sambil } \\
\text { mengucapkannya }\end{array}$ & $31 \%$ & $\begin{array}{l}\text { tidak } \\
\text { baik }\end{array}$ \\
\hline 3. & $\begin{array}{l}\text { Anak bisa } \\
\text { melangkahkan kaki } \\
\text { secara serentak } \\
\text { antara pemain satu, } \\
\text { dua, dan tiga. }\end{array}$ & $19 \%$ & $\begin{array}{l}\text { tidak } \\
\text { baik }\end{array}$ \\
\hline 4. & $\begin{array}{l}\text { Anak mampu sabar } \\
\text { ketika menunggu } \\
\text { giliran bermain } \\
\text { bakiak. }\end{array}$ & $56 \%$ & cukup \\
\hline 5. & $\begin{array}{l}\text { Anak mampu } \\
\text { menyebutkan bentuk } \\
\text { bakiak dalam setiap } \\
\text { kelompok. }\end{array}$ & $81 \%$ & Baik \\
\hline 6. & $\begin{array}{l}\text { Anak mampu } \\
\text { menerapkan sikap } \\
\text { saling tolong } \\
\text { menolong ketika } \\
\text { temannya jatuh. }\end{array}$ & o\% & $\begin{array}{l}\text { tidak } \\
\text { baik }\end{array}$ \\
\hline 7. & $\begin{array}{l}\text { Anak mampu } \\
\text { menegendalikan } \\
\text { emosi ketika } \\
\text { bermain bakiak. }\end{array}$ & $81 \%$ & Baik \\
\hline
\end{tabular}

\begin{tabular}{|l|l|l|l|} 
8. & $\begin{array}{l}\text { Anak mampu } \\
\text { memainkan } \\
\text { bakiak sampai } \\
\text { finish. }\end{array}$ & $63 \%$ & cukup \\
\hline
\end{tabular}

Persentase Ketuntasan Belajar

$$
E=\frac{n}{N} \quad X 100 \%
$$

Keterangan:

$\mathrm{n}=$ jumlah anak yang mencapai $\mathrm{kkm}$

$\mathrm{N}=$ Number of cases ( jumlah frekuensi atau banyaknya individu)

$\mathrm{E}=$ Angka persentase

$$
\mathrm{E}=\quad \frac{10}{16} \times 100 \%=62 \%
$$

Nilai Rata - Rata

$$
\bar{X}=\frac{\sum X}{\sum N}
$$

Keterangan :

$\bar{X}=$ Nilai rata-rata

$\Sigma \mathrm{X}=$ Jumlah semua nilai siswa

$\Sigma \mathrm{N}=$ Jumlah siswa

$$
\begin{aligned}
& X=\frac{\sum X}{\sum N} \\
& =\frac{66}{16}=4,125
\end{aligned}
$$

Data siklus seperti pada diagram dibawah ini: 


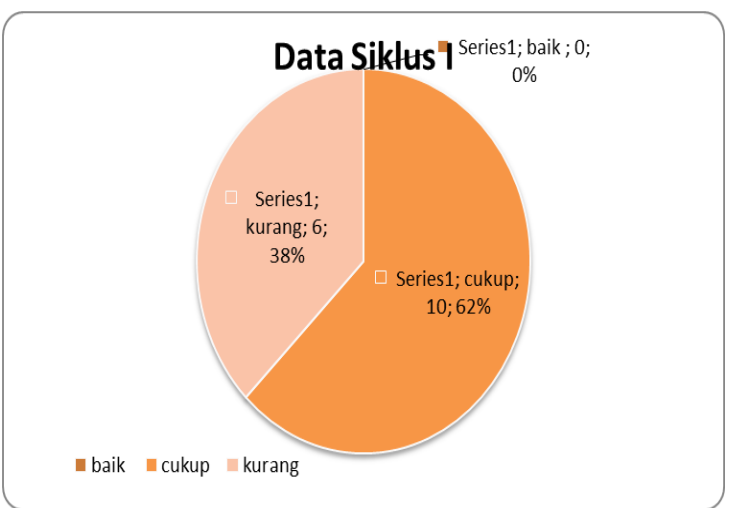

Diagram 1. Persentase Ketuntasan Hasil Perkembangan Anak Pada Siklus I

d. Refleksi

Berdasarkan hasil observasi pada pelaksanaan siklus I. Peneliti mengevaluasi hasil penelitian dengan melakukan perubahan - perubahan yang lebih baik agar metode yang diterapkan bisa lebi optimal. Oleh karena itu, sangat perlu diadkan refleksi berupa perubahan yang sifatnya mendukung terhadap hasil yang diinginkan. Sebelum menginjak siklus II, refleksi harus dilakukan terlebi dahulu.

Dari 16 anak kelas B TK At-taqwa yang dikatakan mencapai KKM hanya 9 anak, hal ini menunjukkan bahwa masih perlu dilakukan siklus II karena yang mencapai KKM hanya 62\%. Sedangkan kriteria kesuksesan yang harus dicapai adalah $80 \%$ dari jumlah anak keseluruhan. Sehingga harus melakukan perubahan serta pengulangan agar mereka mampu mencapai perkembangan yang optimal.

Pelaksanaan pada kegiatan siklus I memperoleh hasil kurang optimal, sehingga ditemukan beberapa permasalahan seperti halnya diatas. Maka, perlu upaya perbaikan dengan melakukan beberapa langkah sebagai berikut:

1. Sebaiknya anak - anak sering - sering dicekoki lagu - lagu yang berhubungan dengan pembelajaran

2. Memberi reward terhadap anak yang berhasil
3. Ketika menunggu giliran sebaiknya dipisah mana yang sudah bermain dan mana yang belum.

4. Guru sebaiknya mengenalkan lebih jelas lagi mana arah kanan dan kiri agar anak tidak bingung.

Hasil perbaikan akan digunakan pada siklus II, dengan harapan agar pada siklus II nanti hasilnya bisa lebih optimal lagi.

\section{Pelaksanaan Siklus 2}

a. Perencanaan

Kompetensi Dasar

1.2 Manusia sebagai ciptaan Tuhan

1.3 Sikap ingin tahu

1.7 Sabar menunggu giliran

1.10 Memiliki prilaku yang mencerminkan sikap kerjasama

1.6 - 4.6 Mengenal benda - benda disekitarnya

3.12 - 4.12 Mengenal keaksaran melalui bermain

1. Kegiatan Pembuka

a. Menerapkan SOP pembukaan

b. Pembacaan qiroati

c. Mempercayai adanya Tuhan melalui Ciptaan-Nya

d. Menyebutkan kendaraan yang ada dikota

e. Menyebutkan kendaraan yang beroda dua dan empat

2. Kegiatan Inti

a. Menerapkan SOP inti

b. Memberikan contoh gambar kendaraan dan gedung - gedung dikota

c. Mencontohkan cara bermainnya

d. Meminta anak untuk membentuk kelompok. Setiap kelompok 3 orang

e. Mengelompokkan roda empat dan roda dua

f. Meminta tiap kelompok untuk memilih memakai gambar roda empat atau roda dua terlebih dahulu 
g. Meletakkan gambar ke dalam wadah yang sudah tertulis angka 4 dan 2 dengan menggunakan bakiak

3. Kegiatan Penutup

a. Penerapan SOP penutup

b. Mengkonfirmasikan kegiatan untuk esok hari

4. Alat dan Bahan

a. Gambar kendaraan dan gedung

b. Wadah dari kertas

c. Permainan tradisional bakiak

b. Pelaksanaan

Dalam tahap pelaksanaan tindakan kelas, peneliti menggunakan permainan tradisional bakiak dalam proses pembelajarannya sesuai rencana pelaksanaan pembelajaran harian (RPPH) yang telah dibuat peneiti sebelumnya.

\section{c. Observasi}

Dalam siklus kedua ini peneliti menggunakan kegiatan dengan sub tema kehidupan dikota. Dimana kegiatan ini anak diminta untuk membedakan kendaraan yang beroda dua dan yang beroda empat, diantara gambar - gambar yang sudah ada.

Tabel 3. Hasil Observasi Kemampuan Sosial Emosional Anak Siklus II

\begin{tabular}{|c|c|c|c|}
\hline No. & Aspek yang diamati & $\begin{array}{l}\text { Siklus } \\
\text { II }\end{array}$ & Kriteria \\
\hline 1. & $\begin{array}{l}\text { Anak mau bermain } \\
\text { meskipun bukan } \\
\text { teman mainnya. }\end{array}$ & $94 \%$ & Baik \\
\hline 2. & $\begin{array}{l}\text { Anak mau } \\
\text { melangkah sesuai } \\
\text { arah kiri dan kanan } \\
\text { sambil } \\
\text { mengucapkannya }\end{array}$ & $50 \%$ & Kurang \\
\hline 3. & $\begin{array}{l}\text { Anak bisa } \\
\text { melangkahkan kaki } \\
\text { secara serentak } \\
\text { antara pemain satu, } \\
\text { dua, dan tiga. }\end{array}$ & $94 \%$ & Baik \\
\hline 4. & $\begin{array}{l}\text { Anak mampu sabar } \\
\text { ketika menunggu } \\
\text { giliran bermain } \\
\text { bakiak. }\end{array}$ & $63 \%$ & cukup \\
\hline 5. & $\begin{array}{l}\text { Anak mampu } \\
\text { menyebutkan bentuk }\end{array}$ & $94 \%$ & Baik \\
\hline
\end{tabular}

\begin{tabular}{|l|l|l|l|} 
& $\begin{array}{l}\text { bakiak dalam setiap } \\
\text { kelompok. }\end{array}$ & & \\
\hline 6. & $\begin{array}{l}\text { Anak mampu } \\
\text { menerapkan sikap } \\
\text { saling tolong } \\
\text { menolong ketika } \\
\text { temannya jatuh. }\end{array}$ & $25 \%$ & $\begin{array}{l}\text { Tidak } \\
\text { baik }\end{array}$ \\
\hline 7. & $\begin{array}{l}\text { Anak mampu } \\
\text { menegendalikan } \\
\text { emosi ketika } \\
\text { bermain bakiak. }\end{array}$ & $81 \%$ & Baik \\
\hline 8. & $\begin{array}{l}\text { Anak mampu } \\
\text { memainkan bakiak } \\
\text { sampai finish. }\end{array}$ & $94 \%$ & Baik \\
\hline
\end{tabular}

\section{Persentase Ketuntasan Belajar}

$$
\mathrm{E}=\underline{\mathrm{N}} \underline{\mathrm{n}} \times{ }_{100} \%
$$

Keterangan:

$\mathrm{n}=$ jumlah anak yang mencapai $\mathrm{kkm}$

$\mathrm{N}=$ Number of cases ( jumlah frekuensi atau banyaknya individu)

$\mathrm{E}=$ Angka persentase

$$
E=\frac{13}{16} \times 100 \%=81 \%
$$

\section{Nilai Rata - Rata}

$$
\bar{X}=\frac{\sum X}{\sum N}
$$

\section{Keterangan :}

$\bar{X}=$ Nilai rata-rata

$\Sigma \mathrm{X}=$ Jumlah semua nilai siswa

$\Sigma \mathrm{N}=$ Jumlah siswa

$$
\begin{aligned}
X=\frac{\sum X}{\sum N} \\
=\frac{95}{16}=5,94
\end{aligned}
$$

Data siklus seperti pada diagram dibawah ini: 


\section{atthufulah

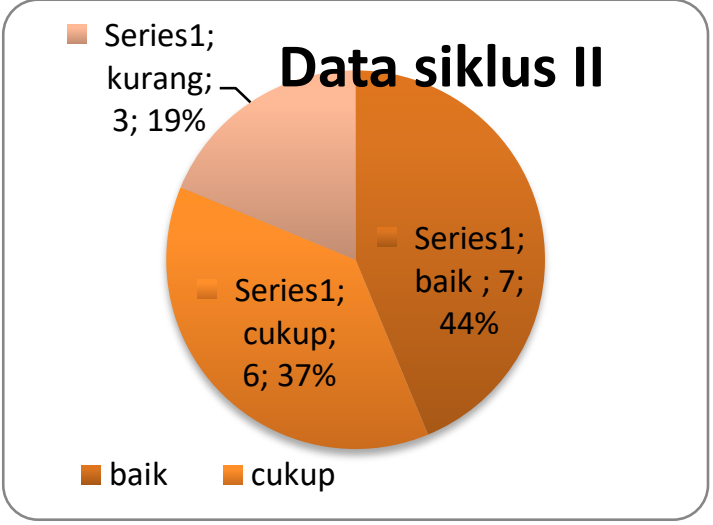

\section{Diagram 2. Persentase Ketuntasan Hasil Perkembangan Anak Pada Siklus II}

\section{d. Refleksi}

Observasi yang dilakukan pada siklus II menunjukkan hasil yang cukup baik dalam mengembangkan sosial emosional anak, tercatat sebanyak 81\% dari 16 anak yang sudah berkembang cukup baik. Sehingga tidak perlu lagi mengadakan perbaikan pada siklus berikutnya.

\section{PEMBAHASAN}

Berdasarkan penelitian pada kedua siklus yaitu siklus I dan siklus II telah ditemukan perbandingan penelitian tingkat kesuksesan disetiap aspek pengamatan dalam setiap indikatornya dan juga sudah di rata - rata perolehan kesuksesan dan sebelum tindakan pembelajaran. Pada prasiklus anak yang mendapatkan kategori nilai baik yaitu 19\%. Anak yang mendapatkan kategori nilai cukup 44\%. Sedangkan anak yang memperoleh dengan kategori kurang yaitu $38 \%$. Adapun hasil dari tindakan siklus I dan siklus II dapat dilihat pada tabel dibawah ini.

Tabel 4. Hasil Persentase Tindakan Siklus I Dan Siklus II

\begin{tabular}{|c|l|r|c|}
\hline No & Pencapaian & Siklus I & \multicolumn{1}{|c|}{$\begin{array}{c}\text { Siklus } \\
\text { II }\end{array}$} \\
\hline 1. & $\begin{array}{l}\text { Pencapaian } \\
\text { Klasikal }\end{array}$ & $6 \mathbf{2} \%$ & $81 \%$ \\
\hline 2. & Nilai rata - rata & 4,125 & 5,94 \\
\hline
\end{tabular}

Tabel 5. Kategori Nilai Prasiklus, Siklus I Dan II

\begin{tabular}{|c|c|c|c|c|c|}
\hline \multirow{2}{*}{$\begin{array}{c}\text { N } \\
\text { o } \\
\cdot\end{array}$} & \multirow{2}{*}{$\begin{array}{c}\text { Kateg } \\
\text { ori }\end{array}$} & \multicolumn{2}{|c|}{ Jumlah } & \multicolumn{2}{c|}{ Persentase } \\
\cline { 3 - 6 } & Nilai & $\begin{array}{c}\text { Siklu } \\
\text { s I }\end{array}$ & $\begin{array}{c}\text { Siklus } \\
\text { II }\end{array}$ & $\begin{array}{c}\text { Siklu } \\
\text { s I }\end{array}$ & $\begin{array}{c}\text { Siklu } \\
\text { s II }\end{array}$ \\
\hline 1 & Baik & o & 7 & 0 & $44 \%$ \\
& & & & & \\
\hline 2 & Cukup & 10 & 6 & $63 \%$ & $38 \%$ \\
\hline 3 & Kurang & 6 & 3 & $38 \%$ & $19 \%$ \\
\hline
\end{tabular}

Rendahnya kemampuan sosial emosional yang dimiliki anak dikarenakan penyampaian guru terhadap peserta didik terlalu monoton, sering terasa jenuh ketika guru menyampaikan materi kepada siswa. Sesuai pada hasil pengamatan siklus I, terbukti adanya peningkatan hasil belajar dari indikator yang akan dicapai jika dibandingkan dengan kondisi awal anak sebelum tindakan, karena pada kegiatan siklus I kegiatan dan metode pembelajaran yang diberikan berbeda dengan sebelumnya. Presentase kemampuan sosial emosional anak pada siklus I mengalami peningkatan daripada prasiklus. Pada prasiklus hasil yang dicapai masih lumayan jauh dari target yang telah ditetapkan. Menrut peneliti hasil ini disebabkan karena anak jarang menggunaan permainan dalam pembelajaran.

Pada siklus I ditemukan adanya permasalahan yang muncul disebabkan oleh faktor internal dari peserta didik maupun faktor eksternal yang disebabkan kurang sempurnanya perencanaan maupun pelaksanaan dari kegiatan pembelajaran dengan menggunakan permainan tradisional bakiak. Karena itu, pada hasil observasi terhadap pelaksanaan tindakan siklus I dilakukan perbaikan - perbaikan agar pada siklus II dapat mencapai hasil sesuai target yaitu lebih baik. Kegiatan pembelajaran pada siklus II menunjukkan keadaan yang lebih kondusif. Siswa terlihat lebih antusias untuk mengikuti proses 
kegiatan belajar. Hampir seluruh peserta didik bisa memainkan bakiak sampai finish tanpa terjatuh. Hasil pencapaian pada setiap pertemuan pada siklus II telah sesuai dengan indikator keberhasilan yang telah ditetapkan.

Dalam proses pembelajaran guru tidak harus menggunakan kegiatan yang monoton pada gambar saja, bisa dengan bermain. Pemanfaatan permainan tradisional dapat digunakan pendidik dalam kegiatan belajar mengajar. Dengan demikian permainan tradisional bakiak sangat memberi pengaruh yang baik dalam membantu mengembangkan keterampilan emosi dan sosial pada siswa.

\section{KESIMPULAN}

Proses pelaksanaan belajar mengajar menggunakan permainan tradisional bakiak yaitu terlebih dahulu guru melakukan apersepsi. Guru menunjukkan alat permainan tradisional bakiak, peneliti mempraktekkan cara bermain permainan tradisional bakiak, mengenalkan arah kanan dan arah kiri, menanamkan sikap saling tolong menolong sesama teman, mampu membedakan bentuk, mengajarkan anak untuk saling bekerjasama dengan baik, kemudian anak mempraktekkan kegiatan yang telah dicontohkan sesuai dengan kelompoknya. Anak sangat antusias ketika melakukan kegiatan belajar mengajar dengan menggunakan sebuah permainan terutama permainan tradisional bakiak. Dan sudah merasa tidak jenuh ketika proses belajar mengajar berlangsung.

dengan masil pelaksanaan pembelajaran tradisional bakiak dapat dilihat pada tingkat keberhasilan kegiatan yang dilakukan pada setiap tahapan siklus yang mengalami peningkatan.Kondisi awal kemampuan social emosional anak sebelum diberikan tindakan yang mampu mencapai kriteria ketuntasan hanya 19\%. Pada siklus I anak yang telah mencapai kriteria ketuntasan meningkat menjadi $62 \%$ karena adanya permainan tradisonal bakiak sebagai penunjang dalam meningkatkan social emosional. Pada siklus II peningkatan kemampuan social emoosional menjadi $81 \%$.

\section{DAFTAR PUSTAKA}

Abdulhak, Ishak, dkk. 2012. Penelitian Tindakan dalam Penelitian Nonformal. Jakarta : PT. Raja Grafindo Persada.

Arikunto, Suharsimi, dkk. 2012. Penelitian Tindakan Kelas. Jakarta : PT. Bumi Aksara.

Arikunto, Suharsimi. 2005. Management Penelitian. Jakarta : PT. Rineka Cipta.

Busthomi, M.Yazid. 2012. Panduan Lengkap PAUD. Jakarta : Citra Publishing.

Fadillah, Mohammad. 2013. Pendidikan Karakter AUD. Yogyakarta : Ar-Ruzz Media.

http://eprints.uny.ac.id/14366/1/skripsi.pdf http://risyazkiya.blogspot.co.id/2012/12/per mainan-tradisional-bakiak.html (25 Maret 2017 09.0o WIB)

Ismail, Andang. 2009. Education Game. Yogyakarta : Pro - U Media.

Kurniati, Euis. 2016. Permainan Tradisional dan Perannya dalam Mengembangkan Keterampilan Sosial Anak. Jakarta : Prenada Media Group.

Mashar, Riana. 2011. Emosi AUD dan Strategi Pengembangannya. Jakarta : Kencana Prenada Media Group.

Meleong, Lexy J. 2014. Metodelogi Penelitian Kualitatif. Bandung : PT. Remaja Rosda Karya.

Montesori, Maria. 2008. The Absorbent Mind. Yogyakarta : Pustaka Pelajar.

Mulyani, Novi. 2016. Super Asyik Permainan Tradisional Anak Indonesia. Yogyakarta : Diva Press.

Mursid. 2016. Pengembangan Pembelajaran AUD. Bandung : PT. Remaja Rosda Karya.

Sanjaya, Wina. 2015. Penelitian Tindakan Kelas. Jakarta : Prenada Media Group.

Saputra, Mayke S Tendja. 2007. Bermain Mainan dan Permainan. Jakarta : PT. Grasinda. 
Seefeldt, Carol, dkk. 20o8. Pendidikan Anak Usia Dini. Jakarta : PT. Indeks.

Sugiyono. 2015. Metode Penelitian Pendidikan Pendekatan Kuantitatif, Dan $R \mathcal{E} D$. Bandung : Alfabetha.

Sugiyono. 2015. Metode Penelitian Tindakan. Bandung : Alfabeta.

Sukidin. 2002. Manajemen Pendidikan Tindakan Kelas. Jakarta : Insan Cendekiawan.

Susanto, Ahmad. 2012. Perkembangan AUD. Jakarta : Kencana Prenada Mediagroup.

Suyandi. 2010. Psikologi Perkembangan AUD. Yogyakarta : PT. Pustaka Insan Madani. Suyanto, Slamet. Strategi Pendidikan Anak. Yogyakarta : Hikayat Publishing. 